\title{
Social Workers Tolerance and Its Development at University Refresher Course
}

\author{
Natalya Ivanovna Nikitina ${ }^{1}$, Svetlana Nikolaevna Tolstikova ${ }^{2} \&$ Veronica Michailovna Grebennikova ${ }^{3}$ \\ ${ }^{1}$ Russian State Social University, Moscow, Russian Federation \\ ${ }^{2}$ Moscow City Pedagogical University, Moscow, Russian Federation \\ ${ }^{3}$ Kuban State University, Moscow, Russian Federation \\ Correspondence: Natalya Ivanovna Nikitina, Russian State Social University, Faculty of Social Work, Pedagogy \\ and uvenology, V. Peak Street, 4, 129226, Moscow, Russian Federation. E-mail: nn0803@mail.ru
}

Received: November 27, 2014 Accepted: December 30, 2014 Online Published: May 15, 2015

doi:10.5539/ass.v11n15p55 URL: http://dx.doi.org/10.5539/ass.v11n15p55

\begin{abstract}
In modern Russia to the vocational education system, is to develop in higher education and training institutions set of conditions for the development of tolerance as an important characteristic of the individual experts socio-pedagogical profile. Manifestations of tolerance as an important characteristic of social workers (professionals working in children's homes, social shelters, centers for social assistance to families and children, geriatric centers in Moscow) with a different experience of employment (from 1 to 18 years) were studied by the authors in the course of fifteen years using valid diagnostic techniques. Identified the relationship of tolerance development social workers with their individually-typological properties and age and gender characteristics of the individual. The article describes the characteristics of the authors developed an individual style manifestation of tolerance: synergy, effectively adaptive, selective.
\end{abstract}

Keywords: social worker, professional development, professional qualities specialist, tolerance

\section{Introduction}

Requirements for professional quality tolerant social educator enshrined in the International Code of ethics and professional social worker, the moral code of the Association of social workers and social workers in Russia, members of the professional code of the Interregional Association of Russian social services, as well as professional qualification characteristics of "social worker", approved by the Ministry of Labour Russia, as well as in professiogram "social worker", who developed scientific researchers (Mardahaev, 2002; Bamford, 1990; Payne, 1999; Asquith, Clark, \& Waterhouse, 2005).

Study of the problem of manifestation of tolerance in professional activities of practicing social workers require access to the scientific works of Russian and foreign teachers and psychologists who have studied the tolerance as an important characteristic of professionals working in the system "man - the man" (Asmolov \& Soldatova, 2001; Bondyreva \& Kolesov, 2003; Bim-Bad, 1994; Markova, 1998; Avery, 2002; Cameron \& Moss, 2011; Bisman, 2004). In these studies, the scientists proved the objective necessity of formation in the social teacher tolerance. This fact is connected with the fact that the individual behavioral and sociocultural characteristics of clients of social educator may be unusual for him. Social educator, being in contact with customers, unwittingly immersed in a specific "heavy" emotional background, peculiar "people with social problems". Near the specialist may arise anxiety, pessimism, aggressiveness. In such circumstances, the work load increases manifestations of tolerance.

After analyzing the different approaches to the interpretation of the concept of "tolerance" (Mendus, 1989; Horton \& Nicholson, 1992; Galeotti, 2002; McKinnon, 2006; Asmolov \& Soldatova, 2001; Oberdiek, 2001; Bondyreva \& Kolesov, 2003) we have developed the author's definition of this category as an important characteristic of the social teacher. Tolerance is a social educator integrative and personal formation (as a socio-psychological phenomenon), which reflects the internal installation specialist to adopt "other I" appears in the implementation of the regulatory role models of professional and ethical conduct situational specialist, as well as in the methods of social interaction syntonic teacher with the subjects personality-business communications (Nikitina \& Tolstikova, 2002). Tolerance is characterized by social teacher understanding and 
acceptance of the individual identity of another person, in the absence of categorical assessment of people, tolerance to physical and psychological discomfort partner, the ability to take into account the peculiarities of character, habits, and attitudes of others, demonstrating the possibility of finding common ground (cooperation) in all situations.

The composition of tolerance as a psychological phenomenon include: a) the orientation of the individual as its system of values and attitudes, which can be attributed to the motivational sphere; b) emotional, psychobiological (sensory) components, c) intellectual and characterological components (Nikitina \& Tolstikova, 2011).

After many years of experimental work (2000-2014 years), we came to the conclusion: a) the development of tolerance in the "high school - a refresher course" proceeds according to the appropriate age Chronotope personality development (student, young professional, social worker, professional); chronotope (Ukhtomsky, 1928). As a relatively closed space-time continuum, which in the context of a systemic, based on deep connections with them is a transformation is in its subject, ie psychologically chronotop includes unity of the characteristic features of a certain age for the activities of the social situation of development, mental structures; b) there is a relationship of tolerance development social workers with their individually-typological properties of age and gender and personality characteristics; c) tolerance as an important characteristic to develop students' high school and adult learners (practitioners) training courses, provided that in the educational process of university and course preparation implemented specialized psycho-educational technologies that simulate professional-role behavior specialist in a variety of situations of personal and business interaction.

\section{Method}

An experimental base for the study were the Russian State Social University (RSSU), Moscow City Pedagogical University (MCPU). The total sample (participants in the experiment for the period from 2000 to 2014) was 3010 people. Of them at various stages of the experimental work in the study included 835 full-time students (day) form of education (age 17 to 23 years) and 862 students of correspondence courses (age 18 to 55 years) in the specialty (the direction of training) "Social pedagogy".

826 practitioners (social workers, the age range of 20 to 60 years) who were trained in refresher courses on the program "Social pedagogy: modern technologies and methods of work" (502 hours).

487 social workers (aged 20 to 55 years) with the experience of professional activities from 1 year to 18 years. These social workers are working in institutions (orphanages, social shelters, centers for social assistance to families and children, geriatric centers in Moscow and the Moscow region), which are the bases of student teaching and internships RSSU and MCPU.

In the empirical part of the study used diagnostic techniques: 1) a technique V. V. Boyko, to identify the level of tolerance of the person (Boyko, 1996); 2) technique for diagnosing personality orientation "Orientation profile" B. Bass; 3) technique to study the self-identity V. V. Stolin and S. R. Panteleeva, 4) methodology K. Thomas, by definition, means of resolving conflict; 5) "Method for studying the reactions of frustration" S. Rosenzweig; 6) "The test of self-actualization (SAT)" E. Shostrom; 7) test I. M. Yusupov by measuring the expression of empathy (Yusupov, 1991); 8) method of determining the semantic units to communicate personality, S. L. Bratchenko; 9) "value orientations" M. Rokeach, 10) 16-factor personality questionnaire R. Cattell; 11) questionnaire K. Leonhard modification Shmisheka to identify character accentuations. In addition, the authors used a modified projective technique A. Kronik and E. Tovbaz study the perceptual social worker interpersonal relationships, as well as the authors developed an original technique "style manifestation of tolerance social educator".

\section{Empirical Study of the Manifestations of Tolerance}

Before the start of training (forming) the experiment was carried out a pilot study. Proanketirovano was interviewed and 358 social workers (professionals working in children's homes, social shelters for minors, centers of social assistance to families and children, geriatric centers in Moscow). Analysis of the survey results and interviews showed that $53 \%$ of professionals are experiencing serious difficulties in communication manifestations of tolerance as an important characteristic that tends to reduce the effectiveness of the professional activity, leading to dissatisfaction with the results of labor, inadequate self-assessment forms.

At the stage of ascertaining experiment to study the characteristics of perception of interpersonal relations future social teachers (university students) was used "projective technique of studying the subject's perception of interpersonal relations. It is found that boys ( 68 men, Mage $=18.5$ years, age range: $17-21$ years) and women (73 women, Mage $=18.5$ years, age range: $17-21$ years) have a different perception and interpret the emotional 
relationship. Girls, in particular, are more likely to see the expression of empathy in human relations (53\% of cases) compared with boys ( $39 \%$ of cases). At the same time, young men often see in human relations display of indifference (37\%) than girls (22\% of cases). They both have a different perception and interpret relations as status-role $\left(\chi 2=10.08 ; \chi^{2} \geq 8.71\right.$; significant differences in $\left.\mathrm{R} \leq 0.01\right)$. Girls often see and perceive the relationship as unequal as superior to the partner (34\% of cases) or the superiority of the partner (30\%), young men respectively, $22 \%$ and $20 \%$ of cases. In turn, the boys tend to see relationships between people as equal more often ( $48 \%$ of cases) than girls ( $36 \%$ of cases).

In general, analysis of the data set of diagnostic methods used in the step of ascertaining experiment showed: there are three groups of high school students who have signs of different styles of tolerance (synergistic, result-adaptive, selective - see the description of the styles below); students underdeveloped reflection; they do not always appreciate their true capabilities. All this has revealed the need for the students specialized psycho-educational work in order to increase positive self-acceptance, obtaining positive dynamics "focus on the interaction" as one of the components of tolerance, development of flexibility of behavior, self-regulation skills.

Multivariate analysis of the results of many years of experimental work on the development of social tolerance of the teacher in the "high school - a refresher course" allows us to conclude that each specialist is unique and original in the field of professional communication, differing in the internal mechanisms of adaptation to the conditions of the communicative situation. Communicative originality of each does not exclude, but implies a certain typical traits of tolerance, common to a group of specialists. Typology developed by the author's individual styles manifestations of tolerance into account their social educator (styles) conditionality is not only natural, individual characteristics, but also the professional activity-related characteristics of a specialist.

Based on the analysis of scientific papers on the issue of individual styles of communication and activities (Allpot, 1937, 1963; Leont'ev, 1997; Markova, 1998; Yamazaki, 2002), as well as based on extensive analysis of empirical (experimental and practical) of the material (prepared 15 years of the study) were identified and justified synergistic, result-adaptive, selective individual styles manifestations of tolerance social educator, which are characterized by different sets of typological features. Thus, for social workers synergistic style is characterized by: focus on interaction (through the questionnaire B. Bass); a high level of empathy; slight predominance of intuition over reflexivity; focus on the process and the result of professional work, a positive emotional climate in childhood and pedagogical teams; kinesthetic representational systems; in conflict situations are most common strategy of cooperation and compromise; more severe anxiety, emotional (the dough K. Leonhard); high extraversion, mobility and dynamism (by R. Cattell personality questionnaires); high scores on flexibility and the synergistic behavior (by "SAT" E. Shostrom); in situations of frustration tendency to bezobvinitelnym permissive forms of emotional and communicative reactions (S. Rosenzweig on the test); for emotional self-control, tend to use self-hypnosis, search activity, the inclusion of resource status; easily orient themselves in a rapidly changing environment, are able to find the right tactics of communicative behavior, create an atmosphere of goodwill.

Social educators effectively adaptive style show predominance of motifs associated with the achievement of its objectives, orientation, as a result, and in the process of professional activity, a slight predominance of reflexivity over intuitiveness; may experience difficulty in empathy, openness; most typical left-hemisphere, auditory representational systems; strategies of behavior in conflict situations prevail compromise, cooperation, competition rarely seen; most pronounced pedantry, jams; introversion; high scores on the adoption of aggression, cognitive needs, support; in situations of frustration tend to be self-incriminating and self-protective form of emotional and communicative reactions (S. Rosenzweig on the test); for emotional self-control most successfully use rationalization, self-persuasion, affirmirovaniya technique, the technique of turning confusion in understanding; stable in a state of tension; may have difficulty in targeting the rapidly changing situation; skillfully control and adjust their communicative behavior as long as it does not lead to the planned results; their unwanted emotional states and associated conditions in children "quenched" by switching to other activities.

For social workers selective style is characterized by: a focus on (the questionnaire B. Bass) on the achievement of results; combination of intuition and reflexivity; difficulties in empathy, acceptance position of the interlocutor; they are most pronounced cyclothymic, can manifest as demonstrative and exaltation; strategies of behavior in conflict situations prevail adaptation, competition, avoidance; they tend to be relatively high emotional lability; have high scores on spontaneity, self-esteem, sociability. In situations of frustration, as a rule, exhibit vneshneobvinitelnye and prepyatstvenno-dominant emotional and communicative reaction (by the test S. Rosenzweig); for emotional self-control most successfully used self-briefing, off-switching technique affirmirovaniya. In dealing with "difficult" children, wards, clients use the suggestive power, showing search activity. 
Or that style displays tolerance social educator in pure form in reality practically does not occur, we can only speak about the prevalence of certain typological implications. At the same time, the heuristic value of the typology of styles manifestations of tolerance social teacher can not be reduced only to a statement of the general and particular: this typology is needed as one of the main reasons - the determination of differentiated work with students (future social teachers), as well as with the audience of course preparation (practitioners) in the training that have different types, and therefore require individualization of training and retraining (Nikitina, 2004; Nikitina \& Tolstikova, 2012; Grebennikova \& Nikitina, 2014).

\section{Training (Forming) the Experiment}

During the experimental work has been approved training "Tolerance social educator: the unity of personal and professional." Much attention has been paid during the training ethno-psychological training, the psychological aspects of gerontology, psychology of religious beliefs. Certain difficulties have arisen in the course of work to change the social and perceptual patterns (anthropological, ethno-national, social status, social role, expressive and aesthetic). Series of classes was devoted to situations in the professional activities of a social educator, requiring a high level of communicative tolerance. These included situations that arise in the course of counseling, in the process of interaction with administration, colleagues, employees, administrative and law enforcement officials, representatives of civil society and religious organizations. In conducting special courses, workshops used interactive teaching methods, individually-oriented suggestoterapiya, psychophysiological Gymnastics, logotherapy, skriboterapiya, bibliotherapy.

\section{Discussion}

At the final stage of the experiment, we compared expert estimates (the experts were qualified social workers and representatives of the administration database practices of universities, teachers and university graduates) and self-evaluation by the participants of the experiment of formation of individual indicators of social tolerance of the teacher (five-point scale was used evaluation) (Table 1, in table shows the average score).

Table 1. The results of peer review and self-esteem participants in the experiment degree of development of individual indicators of social educator manifestations of tolerance in the realities of their professional activities (mah - 5 points)

\begin{tabular}{|c|c|c|c|c|}
\hline measurements & \multicolumn{2}{|c|}{2010 year } & \multicolumn{2}{|c|}{2014 year } \\
\hline \multirow{3}{*}{ indicators } & $\begin{array}{l}\text { Expert. } \\
\text { rating }\end{array}$ & Self-evaluation & $\begin{array}{c}\text { Expert. } \\
\text { rating }\end{array}$ & Self-evaluation \\
\hline & \multicolumn{4}{|c|}{$\begin{array}{c}\text { university ( } \mathrm{n}=135 \text {; Mage }=22 \text { years, age range: } 21-23 \text { years }) / \\
\text { refresher courses }(\mathrm{n}=138 ;\end{array}$} \\
\hline & \multicolumn{4}{|c|}{ Mage $=38$ years, age range: $30-46$ years $)$} \\
\hline $\begin{array}{c}\text { Ability to perceive and adopt features of } \\
\text { other cultures }\end{array}$ & $3.62 / 3.84$ & $4.08 / 4.13$ & $4.26 / 4.53$ & $4.68 / 4.75$ \\
\hline $\begin{array}{l}\text { Skills and attitudes of social perception, } \\
\text { adequate interpretation of communicative } \\
\text { and behavioral responses of different ethnic } \\
\text { groups }\end{array}$ & $3.21 / 3.38$ & $3.24 / 3.67$ & $4.02 / 4.35$ & $4.13 / 4.36$ \\
\hline $\begin{array}{l}\text { Ability to overcome inter-ethnic conflicts in } \\
\text { the environment }\end{array}$ & $3.26 / 3.44$ & $3.21 / 3.42$ & $3.87 / 3.96$ & $3.85 / 4.02$ \\
\hline $\begin{array}{l}\text { Ability to forge personal-business } \\
\text { communication allowing for the religious } \\
\text { beliefs of communicants, the specifics of } \\
\text { their behavior due to religious norms }\end{array}$ & $3.11 / 3.75$ & $3.17 / 3.94$ & $3.62 / 3.74$ & $3.71 / 3.98$ \\
\hline
\end{tabular}

To determine the consistency of the estimates of experts was determined coefficient of concordance $\mathrm{W}$ for each indicator. The calculation of the coefficients of concordance for all indicators showed the consistency of expert opinion on the average (0.52) to strong (0.79), which suggests that a comprehensive evaluation of formation of 
individual indicators manifestations of social tolerance of the teacher in the real world of professional activity is sufficiently accurate.

\section{Conclusion}

Data analysis of long-term experimental work allows us to conclude: a) there are persistent personal qualities that are essential for the success of the development of tolerance, but virtually no educability (eg typological properties of the nervous system, personality traits of temperament); b) the development of tolerance of the social teacher cause sotsiogenetichesky, microenvironmental (psychogenetic), biogenetic factors; c) The characteristic feature of the phenomenon of tolerance social educator is the stability of its manifestations in the realities of professional activity; g) There are psychological and pedagogical technological capabilities compensatory overcome weak links tolerance of the person of the social teacher.

This result is consistent with prior studies that have shown that the implementation in the educational process of "high school - a refresher course" of certain psycho-pedagogical conditions of social educator develops tolerance for individual diagnosed indicators (Postalyuk, 1992; Bim-Bad, 1994; Kodzhaspirova, 2005). The present study provides additional evidence that the mechanisms of tolerance development of social educator are: self-knowledge; identification; internalization; externalization and self-realization; self-education; reflection (Gallegos, 1982; Horton \& Nicholson, 1992; Vulfov, 2002; Rean \& Kolominsky, 2000; Nikitina et al., 2014). Improve the efficiency of the process of development of tolerance social teachers in the process of continuous training in the "high school - training" promote psycho-pedagogical professional and educational technology with student-activity-based, interactive and dialogical, adaptive and context-orientation (eg, personalized training (Galkina \& Nikitina, 2012); counseling university students and adults enrolled in courses for personal and professional and personal problems (Abreu, Chung, \& Atkinson, 2000), specialized workshops, together with representatives of employers.

\section{Funding}

This article was prepared in the framework of the state task of Ministry of Education and Science of Russian Federation 2014/601 (project code 3106).

\section{References}

Abreu, J. M., Chung, R. H. G., \& Atkinson, D. R. (2000). Multicultural counseling training: Past, present, and future directions. The Counseling Psychologist, 28, 641-656. http://dx.doi.org/10.1177/0011000000285003

Allpot, G. W. (1937). Personality: A Psychological Interpretation. New York: Henry Holt \& Company.

Allpot, G. W. (1963). Pattern and groutch of personality. New York: Holt, Rinehart and Winston.

Asmolov, A., \& Soldatova, G. (2001). On the meaning of "tolerance". Age of Tolerance: Research and journalistic Gazette, 1, 8-19.

Asquith, S., Clark, C., \& Waterhouse, L. (2005). The Role of the Social Worker in the 21 Century: a Literature Review. Edinburgh: Scottish Executive.

Avery, P. (2002). Teaching tolerance: What research tells us. Social Education, 66(5), 270-276.

Bamford, T. (1990). The Future of Social Work. Basingstoke, Macmillan.

Bim-Bad, B. M. (1994). Anthropological basis of theory and practice of modern education. Moscow: Publishing house of University of Russian Academy of Education.

Bisman, C. (2004). Social work values: the moral core of the profession. British Journal of Social Work, 34(1), 109-123. http://dx.doi.org/10.1093/bjsw/bch008

Bondyreva, S. K., \& Kolesov, D. V. (2003). Tolerance (introduction to the problem). Moscow: Publishing house of the Moscow Social-psychological Institute.

Boyko, V. V. (1996). Energy of emotions in communication: a look at themselves and others. Moscow: Information Publishing House "Filin".

Cameron, C., \& Moss, P. (Eds.). (2011). Social Pedagogy and Working with Children and Young People: Where Care and Education Meet. London: Jessica Kingsley.

Galeotti, A. (2002). Toleration as Recognition. Cambridge: Cambridge University Press. http://dx.doi.org/10.1017/CBO9780511487392

Galkina, T. E., \& Nikitina, N. I. (2012). Personalized approach in the system of training and additional professional education of specialists of social sphere. Innovations in education, 6, 13-27. 
Gallegos, J. S. (1982). The ethnic competence model for social work education. In B. W. White (Ed.), Color in a white society (pp. 1-9). Silver Spring, MD: National Association of Social Workers.

Grebennikova, V. M., \& Nikitina, N. I. (2014). Continuing education as a cultural-historical problem. Questions of philosophy, 4, 79-84.

Horton, J., \& Nicholson, P. (Eds.). (1992). Toleration: Philosophy and Practice. London: Ashgate Publishing Company.

Kodzhaspirova, G. M. (2005). Pedagogical anthropology. Moscow: Gardariki.

Leont'ev, A. A. (1997). Psychology of communication. Moscow: Publishing House "Smysl".

Mardahaev, L. V. (2002). Professional culture of a social pedagogue. In V. A. Nikitin (Ed.), Social pedagogy (pp. 234-236). Moscow: Moscow Social-psychological Institute.

Markova, A. K. (1998). Psychology of professionalism. Moscow: international humanitarian Fund "Znanie".

McKinnon, C. (2006). Toleration: A critical introduction. London: Routledge. http://dx.doi.org/10.4324/9780 203300640

Mendus, S. (1989). Toleration and the Limits of Liberalism. London: Macmillan Education.

Nikitina, N. I. (2004). Professional self-education of future social workers in the system of continuous education (M. S. thesis). Institute of General Education of Ministry of Education of the Russian Federation, Moscow.

Nikitina, N. I., \& Tolstikova, S. N. (2002). Communicative tolerance in the system professionally significant qualities of social educator. Scientific notes of the Moscow Humanitarian Pedagogical Institute, 1, 33-39.

Nikitina, N. I., \& Tolstikova, S. N. (2011). Development of professionally-communicative tolerance specialists socio-pedagogical profile in continuing education. Scientific notes of the Russian State Social University, 7(95), 140-145.

Nikitina, N. I., \& Tolstikova, S. N. (2012). Professional communicative culture of specialists in the sphere of international cooperation: the development context. Human capital, 2(38), 160-163.

Nikitina, N. I., Galkina, T. E., Tolstikova, S. N., Avtionova, N. V., Volenko, O. I., \& Grebennikova, V. M. (2014). The characteristics of the model for development of communicative deontological culture of school principals in the system of their refresher training. Life Science Journal, 11(12), 542-546.

Oberdiek, H. (2001). Tolerance: Between Forbearance and Acceptance. Lanham, Md.: Rowman and Littlefield.

Payne, M. (1999). The moral bases of social work. European Journal of Social Work, 2(3), 247-258. http://dx.doi.org/10.1080/13691459908412193

Postalyuk, N. Y. (1992). Pedagogy of cooperation: the way to success. Kazan: Kazan State University.

Rean, A. A., \& Kolominsky, Y. L. (2000). Social and pedagogical psychology. St. Petersburg: publishing house "Piter".

Ukhtomsky, A. A. (1928). Psychoanalysis and physiological theory of conduct. Leningrad.

Vulfov, B. Z. (2002). Pedagogy of reflection and professional culture of a teacher. Moscow: Moscow Humanitarian Pedagogical Institute.

Yamazaki, Y. (2002). Learning styles and typologies of cultural differences: A theoretical and empirical comparison. Working paper 02-1. Department of Organizational Behavior, Weatherhead of School of Management, Case Western Reserve University, Cleveland, OH.

Yusupov, I. M. (1991). Psychology of mutual understanding. Kazan: Publishing house of Kazan University.

\section{Copyrights}

Copyright for this article is retained by the author(s), with first publication rights granted to the journal.

This is an open-access article distributed under the terms and conditions of the Creative Commons Attribution license (http://creativecommons.org/licenses/by/3.0/). 